\title{
TUTELA CAUTELAR COMO GARANTIA FUNDAMENTAL
}

\section{Edilson Santana Gonçalves Filho}

Defensor Público. Pós-graduado em Direito Processual (Turma IV FA7). Autor do livro A Eficácia Horizontal dos Direitos Fundamentais - sua vinculação às relações particulares.

edilsonsantanagf@hotmail.com

Sumário: Introdução. 1. A Clássica Concepção da Tutela Cautelar de Piero Calamandrei. 2. A Tutela Cautelar para Ovídio Batista. 3. A Tutelar Cautelar e o Novo Código de Processo Civil. 4. A Constitucionalização do Direito, do Processo e das Tutelas de Urgência. 5. Direito e Garantia Fundamental. Conclusão. Referências.

Resumo: O presente estudo objetiva realizar um exame da tutela cautelar, analisada sob diversos enfoques. Partindo das duas mais destacadas escolas que versam sobre o assunto, materializadas nas teorias de Piero Calamandrei e Ovídio Araújo Batista da Silva, observar-se-á tratar-se de proteção instrumental da mais elevada importância, apta, por demais das vezes, à defesa das garantias mais valiosas do ser humano, consagradas nos direitos fundamentais do homem cidadão. Bem por isso, adquire o status de garantia fundamental. A pesquisa foi elaborada dentro de uma abordagem descritivo-analítica do tipo bibliográfica e documental.

Palavras-chave: Processo Cautelar. Tutela Cautelar. Devido Processo Legal. Piero Calamandrei. Ovídio Araújo Batista da Silva. Tutela de Urgência. Garantia Fundamental.

\section{INTRODUÇÃO}

O tempo é fato ineliminável, não podendo ser desconsiderado em qualquer ordenamento jurídico real.

As leis do processo, todavia, podem reduzir os efeitos negativos passíveis de serem causados pela demora na efetivação dos direitos, afastando as inconveniências decorrentes. Devem, assim, sempre buscar uma afeição às exigências do caso concreto, sem jamais suprimir o fator temporal.

A tutela cautelar, desse modo, é um instrumento apto a reduzir os inconvenientes que decorrem do tempo.

O modelo adotado pelo legislador brasileiro no Livro das Cautelares em 1973 sofreu uma radical transformação em 1994, com a Lei 8.952 daquele ano, a qual instituiu a tutela antecipada no direito pátrio.

A matéria é objeto de acirradas discussões, não havendo uma posição pacífica e prevalente.

O que não se discute, todavia, é a importância e imprescindibilidade de um processo apto a proteger o direito da parte, sempre que o fator temporal seja inimigo de sua efetividade. 


\title{
1 A Clássica Concepção da Tutela Cautelar de Piero Calamandrei
}

Levanta-se como eminente expoente da compreensão denominada clássica, do processo cautelar, o jurista Piero Calamandrei. Bem por isso costume-se extrair de seus ensinamentos as características marcantes dessa corrente, dentre as quais destacam-se a instrumentalidade, provisoriedade e o perigo na demora.

Nessa linha, com precisa concisão, aponta José dos Santos Bedaque (1988, p. 34):

\begin{abstract}
As características fundamentais dessa modalidade de tutela são a instrumentalidade, a provisoriedade e a sumariedade. Guarda com a tutela final relação de subordinação instrumental, pois visa a preservar sua efetividade, pelo que carece de autonomia. Por isso é provisória ou interina, ou seja, deixa de existir se o direito, para cuja proteção foi admitida, não for reconhecido afinal, no provimento definitivo. Tendo em vista a urgência que lhe é inerente, a tutela cautelar se caracteriza pela sumariedade da cognição.
\end{abstract}

Como primeira nota característica a instrumentalidade revela a ideia de ser, o procedimento cautelar, instrumento fadado à proteção do processo principal. Objetiva, dessarte, assegurar a eficácia da ação definitiva, a qual servirá, por seu turno, à consecução do exercício do direito almejado.

Diz-se, por isso, haver nas tutelas cautelares uma "instrumentalidade qualificada ou ao quadrado", posto constituírem-se, em verdade, meio dispostas à consecução de um procedimento definitivo, o qual, por sua vez, mostra-se apto à concessão do bem da vida mirado. São, por assim dizer, instrumento do instrumento, ou, nas palavras de Calmon de Passos (1984, p. 46) "processo a serviço do processo, não processo a serviço do direito material".

De mais a mais, essa nota instrumental é qualificada de hipotética, posto voltada para a hipótese de que aquele que pleiteia eventualmente possua razão.

Por provisoriedade, segundo traço característico, Calamandrei expressa a limitação da duração dos efeitos da tutela cautelar.

Nesse sentido, os procedimentos cautelares não se entremostram idôneos a regulamentar definitivamente a relação de direito material controvertida. Não possuem, assim, autonomia, mantendo-se ligados ao provimento final derradeiro e principal, destinando-se a produzir os efeitos necessários à prolação daquele.

Os efeitos jurídicos acauteladores, por serem provisórios, têm duração limitada ao período de tempo que intermedeia entre o processo cautelar e a promulgação de uma decisão final ou substitutiva num procedimento principal.

Nada obstante, “A concepção de provisório para Piero Calamendrei tem incluída em seu interior a ideia de substituição e, por via de consequência, de antecipação", afirma com correção Jaqueline Mielke Silva (2009, p. 25).

A peculiaridade reside no fato de que se o provisório é substituído por algo definitivo, isso representa a existência de uma antecipação dos efeitos finais. Logo, é forçoso reconhecer a satisfação ou, em outros termos, a existência de cautelares satisfativas.

Destarte, as medidas cautelares poderiam assumir não somente o papel de garante da efetividade jurisdicional. Sem embargo, se mostrariam aptas à função de economia processual. Nessa esteira, nem sempre seria necessário e imprescindível, sob pena de ineficácia, um processo posterior com o fito de alcançar cognição plena. 
Cumpre ainda mencionar o perigo de dano que pode derivar do atraso ocasionado pela inevitável lentidão do procedimento ordinário (ou definitivo), configurando aquilo doutrinariamente denominado por periculum in mora.

A prestação jurisdicional para ser eficaz necessita, por mais das vezes, ser proferida sem atraso. Doutra banda, o procedimento comum demanda tempo para ser efetivado com presteza. A tutela cautelar representa, nesse diapasão, ponderação entre tais necessidades.

A demora que visa afastar verifica-se no perigo de a execução se frustrar, ante a ameaça concreta causada por determinado acontecimento. Noutras vezes, o próprio tempo necessário ao desenvolvimento do processo, por si só, representa perigo de dano.

À guisa de remate, pode-se apontar diversos dispositivos legais apostos no Código de Processo Civil - CPC voltados para concepção de tutela cautelar clássica (de Calamandrei), dentre os quais destacam-se os artigos 796, 806 e 808, os quais trazem em seu bojo a ideia de instrumentalidade e provisoriedade dos procedimentos cautelares.

\section{A Tutela Cautelar para Ovídio Batista}

Como traços marcantes da tutela cautelar, na visão de Ovídio Batista, exsurgem: preventividade; temporariedade; existência de situação cautelanda; autonomia; iminência de dano irreparável; sumariedade da cognição. Passa-se a discorrer:

$\mathrm{Na}$ concepção do supramencionado jurista, a proteção cautelar encontra-se inserida no âmbito da tutela de simples segurança. Quer com isso dizer que sua função principal é assegurar direitos, sem jamais satisfazer, contrapondo-se ao conceito de antecipação de tutela, a qual se dá com satisfação.

Não há, dessarte, como falar em antecipação dos efeitos pretendidos em sede cautelar. Daí falar-se em preventividade como marca desse tipo de provimento jurisdicional. Igualmente, deve ser temporário. A sentença que o contém jamais poderá investir-se na imutabilidade inerente à coisa julgada material.

A característica da temporariedade se revela essencial para construção do raciocínio perfilhado por Ovídio, ao passo que a partir do momento no qual se concebe a cautelar como algo temporário, e não provisório ${ }^{1}$, resta afastado o imbróglio doutrinário e jurisprudencial existente entre aquela e a tutela antecipada. A provisoriedade seria característica dessa última.

A eficácia do provimento cautelar, posto que temporária, perdurará enquanto durar a situação de perigo a que está exposto o interessado, servindo de amparo à construção de uma tutela definitiva.

Por sua vez, a antecipação da tutela equivaleria ao próprio efeito definitivo almejado, antecipado em sua concessão, vigendo provisoriamente até decisão final na demanda. ${ }^{2}$

Em suma, a função da tutela cautelar não seria proteger o processo principal, como afirmava a doutrina clássica, mas sim resguardar o direito da parte, sem jamais satisfazê-lo. Referido direito, seja subjetivo, seja a uma pretensão, ação ou exceção, identificaria uma situação carente de proteção ${ }^{3}$, autorizando o uso do meio protetivo cautelar.

\footnotetext{
1 Adotando-se a provisoriedade como um dos elementos da proteção cautelar, como o fez Piero Calamandrei, inevitavelmente acaba-se por inserir a possibilidade de provimentos antecipatórios em seu âmbito. Daí a razão pela qual reconheceu em sua doutrina a existência de cautelares satisfativas.

2 Retirando da cautelar o aspecto provisório, afasta-se, por conseguinte, as medidas satisfativas em seu âmbito, as quais restam enquadradas como antecipação de efeitos da sentença final.

3 É o que se denominou situação cautelanda.
} 
A doutrina ora em análise no presente tópico, partindo de uma base diversa (temporariedade), afasta, assim, em quaisquer casos, o reconhecimento da satisfação em tutela cautelar. Essa visaria única e exclusivamente a segurança de direitos. Havendo satisfatividade estaremos diante do instituto da tutela antecipada.

De mais a mais, tendo por objetivo supramencionada proteção, o processo cautelar não necessariamente deverá se estar vinculado a um processo principal. Trata-se da autonomia cautelar. Não depende, portanto, do processo principal, em razão de não ter por papel sua proteção. A partir daí, observa-se a não concordância com a função instrumental do processo cautelar, proposta pela doutrina clássica.

Nada obstante, o periculum in mora também não seria um requisito necessário à concessão da tutela protetiva, mas, o seria, o risco de dano iminente. É que, havendo perigo na demora deve se antecipar os efeitos (tutela antecipada), e, consequentemente, satisfazer.

Por fim, insta salientar a nota denominada sumariedade da cognição, verificada tanto sob o ponto de vista material (conhecimento não exauriente ou superficial da matéria), quanto formal (exigindo uma forma sumária de procedimento por via do qual ela haverá de se realizar), considerando a urgência como premissa constante e impregnada em todo provimento cautelar.

Em sendo assim, "Pode-se dizer que o juízo de mera plausibilidade do direito para cuja proteção se invoca a segurança é não apenas pressuposto, mas igualmente limite desta modalidade especial de atividade jurisdicional”, consoante aduz Mielke Silva (2009, p. 37).

Conclui-se, daí, sustentar-se a tutela de urgência em juízo de verossimilhança, traduzido em cognição sumária.

\section{A Tutelar Cautelar e o Novo Código de Processo Civil}

O famigerado Novo Código de Processo Civil, em vias de aprovação no Congresso Nacional, pretende trazer maior celeridade à seara processual, sem deixar de lado valores outros igualmente importantes.

No tocante às cautelares, certamente procurando resolver, ou ao menos diminuir, o imbróglio existente entre esta e a tutela antecipada, traz seção destinada às Tutelas de Urgência, acabando com a partição atualmente existente entre tutela cautelar e antecipatória.

A medida poderá ter natureza satisfativa ou não ${ }^{4}$, ser concedida antes ou no curso do processo, por iniciativa da parte ou de ofício, neste último caso de forma excepcional ou quando autorizado por lei.

Para a concessão da medida de urgência, serão exigidos elementos que evidenciem a plausibilidade do direito, bem como a demonstração de risco de dano irreparável ou de difícil reparação.

Levantam-se vozes, já agora, afirmando a expressa possibilidade da concessão de cautelares satisfativas, em razão da novel redação. Defendem outros que, quando satisfativa, estaremos diante de antecipação da tutela, não obstante o novel diploma não utilize essa expressão.

Demais disso, se poderia agora reconhecer, sem celeumas, a possibilidade de concessão de tutela antecipada de ofício, mesmo que sob o título de tutela de urgência? Ou as antecipatórias teriam sumido de vez do ordenamento?

\footnotetext{
${ }^{4}$ O novo diploma utiliza a expressão satisfativa ou cautelar.
} 
Como se vê, longe de acabar com as discussões acerca das divergências existentes entre as medidas cautelares e as antecipatórias de tutela, o Novo Código já é motivo de cizânias doutrinárias, com as quais deveremos conviver por mais alguns anos.

\section{A Constitucionalização do Direito, do Processo e das Tutelas de UrGÊNCIA}

O fenômeno denominado constitucionalização das tutelas de urgência (em que se inclui a cautelar) é consequência do mesmo fato observado no âmbito do processo (em geral), que, por sua vez, deriva da constitucionalização do direito como um todo, motivo pelo qual, compreendendo o último se chega ao primeiro.

Uma das principais mudanças de paradigma que, no âmbito do direito constitucional, foi responsável pela constitucionalização do direito, refere-se à quebra do arcaico pensamento, ainda hoje arraigado em alguns ordenamentos, de que os direitos fundamentais possuem aplicação apenas nas relações do tipo "Estado-cidadão".

Sabe-se hoje que não é somente o Estado que pode ameaçar as garantias essenciais do cidadão, mas também outros particulares.

Embora hoje nos pareça óbvio, a ideia de Constituição como norma de caráter jurídico, dotada de coercibilidade e imperatividade, demorou algum tempo para ser concebida.

No panorama liberal, a Constituição não interferia no campo das relações particulares, as quais eram disciplinadas pela legislação ordinária, encontrando-se especialmente no Código Civil, centro das projeções dos interesses sociais da classe burguesa dominante. Apenas com o Surgimento do Estado Social a Carta Magna passou a prever, de maneira geral, aspectos relacionados à economia, ao mercado e aos direitos oponíveis em face de atores privados, como os trabalhistas, projetando-se, assim, na ordem civil.

Um dos obstáculos basilares para o reconhecimento da Constituição como centro de valores de um ordenamento transmudava-se na concepção de que as normas apostas nos textos constitucionais, referentes à esfera jurídico-privada, eram meramente programáticas, desvestidas de eficácia imediata, necessitando sempre da atividade do legislador infraconstitucional para produzirem seus efeitos.

Dessa forma, a falta de efetividade das normas constitucionais contribuíam, e ainda contribuem, para gerar um enfraquecimento da credibilidade da Constituição, impedindo a formação de um sentimento patriótico-constitucional entre o povo, transformando o texto supremo em meras promessas sem nenhuma eficácia social. A Carta Maior passa a ser vista como um calhamaço de utopias de pouca, ou nenhuma, validade prática.

Quando se fala em constitucionalização do direito e, consequentemente, do processo e das tutelas de urgência (dentre as quais se inclui a cautelar), deve-se ter em vista a ideia de irradiação dos efeitos das normas constitucionais nos demais ramos do ordenamento, por meio de um processo lento, o qual pode se dar por diversas formas, sobretudo por meio de reforma legislativa.

Gunnar Folke Schuppert e Christian Bumke apontam esta como a mais efetiva e menos problemática forma de constitucionalização, realizando-se por meio de reformas gerais ou pontuais na legislação infraconstitucional, adaptando-a às prescrições apostas na Carta Maior.

Desse modo, o principal papel do poder legislativo como constitucionalizador do direito se desenvolve na sua função de adequar a legislação ordinária aos preceitos constitucionais. 
Ainda segundo citados autores, dão impulso ao processo o judiciário, na atividade de aplicar as normas fundamentais, e a doutrina, responsável pela formação imprescindível do alicerce teórico para o desenvolvimento do tema.

A Constitucionalização, portanto, é um processo pelo qual as normas constitucionais penetram nos demais ramos do ordenamento, já que trazem em seu bojo o norte essencial ao desenvolvimento de um ordenamento jurídico unitário e coeso. Assim, obedecendo aos parâmetros traçados constitucionalmente, as demais leis infraconstitucionais se embebedam nas proposições de justiça apostas pelo legislador constitucional, as quais nada mais são que a vontade do povo.

Daniel Sarmento (2004), um dos pioneiros no que se refere ao estudo doutrinário da aplicação dos direitos fundamentais em relações priv das no Brasil, aponta para uma Dimensão Objetiva dos direitos fundamentais. O pensamento prende-se ao reconhecimento de que nos direitos de natureza fundamental estão contidos os valores mais importantes da comunidade, os quais, através dos princípios constitucionais que consagram, penetram nos demais ramos ordenamento jurídico, modelando suas leis e institutos.

Bem por isso, tratar-se, a Constitucionalização, de um movimento necessário para pautar as relações privadas em parâmetros mais justos, onde se concebe a Constituição como o topo hermenêutico direcionador da interpretação do restante do ordenamento, para, com isso, conformar o direito infraconstitucional nos valores da Lei Maior.

Destarte, as normas de cunho fundamental, no mínimo, produzirão efeitos hermenêuticos, condicionando a interpretação e integração do sistema jurídico, vinculando o legislador, servido de base para a criação de leis em conformidade com os seus preceitos e, ainda, a decretação da inconstitucionalidade daqueles já existentes em desconformidade com suas previsões.

Nesse diapasão, o final dos anos sessenta e princípio da década de setenta foram marcados pelo advento de uma renovação do direito processual civil, voltada a enfatizar a origem constitucional de institutos processuais, como, ex vi, o princípio do contraditório à luz de determinações constitucionais.

Surge aí a concepção do direito de ação como aquele direito subjetivo público, garantido constitucionalmente como direito de petição.

A partir de então ensejaram-se esforços no sentido de adaptar o direito processual às exigências constitucionais, tornando-o compatível com os ditames relacionados ao processo apostos no bojo das Constituições, como o devido processo legal, acesso ao poder judiciário e igualdade entre as partes, num nítido processo de constitucionalização.

\section{Direito e Garantia Fundamental}

A expressão "Direitos Fundamentais" surgiu na França, por volta de 1770, como fruto do movimento deflagrador da Declaração dos Direitos do Homem e do Cidadão, vindo a alcançar, tempos após, lugar imprescindível nas Cartas Constitucionais de todo o mundo.

Formular um conceito fechado, sintético e preciso, definindo o que são direitos fundamentais não é tarefa das mais simples, antes de tudo, em virtude de sua transformação ao longo da evolução histórica. Aumenta essa dificuldade o fato de se utilizarem várias expressões quando nos referimos aos tais, como direitos humanos, direitos naturais, direitos individuais do homem e do cidadão etc., o que acaba por gerar uma confusão entre tais institutos, que, em verdade, encontram-se entrelaçados de forma quase que indissociável. 
Oscar Vilhena Vieira (1999, p. 36) conceitua, de maneira bastante didática, "Direitos Fundamentais" como sendo "a denominação comumente empregada por constitucionalistas para designar o conjunto de direitos da pessoa humana expressa ou implicitamente ${ }^{5}$ reconhecidos por uma determinada ordem constitucional." Chama atenção para o fato de que estes encontram-se positivados, e servem de veículo para a incorporação dos direitos da pessoa humana pelo Direito interno.

Destarte, Direitos, ou Princípios Constitucionais, Fundamentais são normas essenciais, as quais conferem sistematicidade à Constituição, servindo de parâmetros para todas as demais regras trazidas à baila pelo ordenamento jurídico, minimizando possíveis conflitos de leis, por meio de uma interpretação conforme os preceitos fundamentais, e garantindo o mínimo necessário ao homem-cidadão.

Ocupam, assim, o mais alto grau na escala normativa, identificando-se com os mais supremos valores humanos, culturais, filosóficos, políticos, traduzindo o melhor da vontade de toda a humanidade para o desenvolvimento de uma sociedade justa. Possuem em seu âmago ligação direta com o universo moral dos direitos da pessoa humana.

São, deste modo, um parâmetro estabelecido do que se busca pela sociedade, de modo que o interesse por ele protegido deve prevalecer sobre outros de cunho não fundamental. Por sua importância, possuem aplicação imediata, ou seja, não podem ter sua aplicabilidade retardada pela inexistência de leis regulamentadoras..

Modernamente, os direitos fundamentais apresentam-se como garantias de primeira, de segunda e de terceira dimensões ${ }^{6}$, segundo a evolução histórica em que passaram a ser, cronologicamente, reconhecidos. Referida divisão nos remete ao lema da Revolução Francesa: liberdade, igualdade e fraternidade.

Importante frisar que não existe hierarquia ou grau de importância entre referidas dimensões, Importante frisar que não existe hierarquia ou grau de importância entre referidas dimensões, motivo pelo qual alguns doutrinadores preferem a utilização do vocábulo "dimensão" dos direitos fundamentais em detrimento da expressão "geração", que daria uma ideia de que cada nova geração adviria em substituição à anterior.

Desta feita, correspondem os direitos de primeira geração às liberdades clássicas ou formais (direitos civis e políticos), os de segunda identificam-se com as liberdades positivas ou concretas (direitos sociais, econômicos), enquanto os direitos de terceira geração materializam-se nas titularidades coletivas (atribuídos genericamente a todos os indivíduos ou cidadãos), consagrando o princípio da solidariedade.

Considera-se que se deu na França a consagração "jurídico-positiva" dos direitos de índole fundamental, com a Declaração dos Direitos Fundamentais do Homem e do Cidadão (26.08.1789) e com as Constituições de 1791 e 1793.

Desde que assumiram caráter concreto de normas positivas na Carta Magna, passou sua natureza a ser constitucional, o que já constava de maneira expressa nas Declarações dos Direitos do Homem e do Cidadão, mais especificamente em seu art. 16, o qual previa que a adoção das garantias de cunho fundamental seriam elementos essenciais ao próprio conceito de constituição.

\footnotetext{
${ }^{5} \mathrm{Os} \S \S 2^{\circ}$ e $3^{\circ}$ do art. $5^{\circ}$ da $\mathrm{CF} / 88$ apontam claramente para uma abertura voltada ao reconhecimento de outros direitos fundamentais não constantes explicitamente no texto constitucional.

${ }^{6} \mathrm{O}$ professor Paulo Bonavides defende a existência de uma quarta geração dos direitos fundamentais, os quais, decorrentes da globalização política, se introduzem na esfera da normatividade jurídica, o que corresponde à derradeira fase de institucionalização do Estado Social.
} 
Não basta, entretanto, que um direito seja reconhecido e declarado, sendo imprescindível garanti-lo, porquanto virão ocasiões em que será discutido e violado. Ruy Barbosa (1978, p. 121) já ensinava haver "no texto da lei fundamental as disposições meramente declaratórias, que são as que imprimem existência legal aos direitos reconhecidos, e as disposições assecuratórias, que são as que, em defesa dos direitos, limitam o poder. Aquelas instituem os direitos; estas, as garantias."

Não são nítidas, todavia, a linhas divisórias entre direitos e garantias. Não raro vê-se confusão doutrinária e legislativa. O próprio legislador constituinte de 1988 não teve acuidade ao tratar do tema, enunciando-o no Título II (Dos direitos e garantias individuais), sem, contudo, apartar as duas categorias, deixando à doutrina missão de desvendar onde estão os direitos ou se acham as garantias.

Paulo Bonavides (2000), dissertando acerca da diferença entre direitos e garantias fundamentais, ressalta que em casos excepcionais é impossível distinguir tais institutos, os quais, todavia, no geral, são dissociáveis. Não raro, juntam-se na mesma disposição (norma) a fixação da garantia e a declaração de direitos. Segundo suas lições, os direitos fundamentais, por suas estrutura, natureza e função, constituem-se em direitos propriamente ditos, por um lado, e garantias, por outro. As garantias visam defender os direitos contra certas classes de atentados.

Doutrinariamente, apontam-se três sentidos para a expressão "garantias fundamentais": reconhecimento positivado nas constituições dos direitos fundamentais; prescrições que vedam determinadas ações do poder público; recursos jurídicos destinados a fazer efetivos os direitos que assegura. ${ }^{7}$

Tais vantagens (direitos) asseguradas podem ser auferidas sem a utilização das garantias. Essas, porém, são instrumentos, servindo como meio de obtenção daqueles benefícios (direitos) constitucionalmente afirmados, sempre que de alguma forma sejam negados ou violados. São, destarte, direitos instrumentais concedidos para proteção, defesa e concretização de outras normas principais e substanciais.

Nesse sentido, o direito processual cautelar não se perfaz em um fim em si mesmo, mas em instrumento destinado à tutela de um direito substancial, público ou privado. Está, em suma, a serviço deste último (do direito substancial), tendo por função garantir sua efetividade.

A síntese mais formosa e lapidar dessa acepção de garantias constitucionais encontra-se gravada no axioma de no 16 da Declaração Francesa dos Direitos do Homem e do Cidadão de 1789, onde se lê: "Toda sociedade na qual a garantia dos direitos não se acha assegurada nem a separação dos poderes estabelecida não tem Constituição.”

À guisa de conclusão, vale repisar poderem os direitos fundamentais consagrados pela Constituição ficar sem qualquer sentido, se não viessem acompanhados de concretas ações que conferissem o devido alcance prático. Bem por isso a Carta Maior já previu uma série de possíveis ações, verdadeiros direitos de ordem processual, visando basicamente a obtenção de medidas judiciais específicas.

Tradicionalmente apontam-se como típicas e expressas garantias de tal natureza o habeas corpus, o mandado de segurança e o mandado de injunção. Não se resumem a essas, todavia. Podem elas decorrer, implicitamente, de regras trazidas na Carta Constitucional, não necessitando, de forma inarredável, constar expressamente de dispositivo específico aposto no corpo constitucional. É o que decorre do direito ao devido processo legal, estabelecido na Constituição Federal vigente.

\footnotetext{
${ }^{7}$ É nesse último conceito (recursos jurídicos destinados a fazer efetivos os direitos que assegura) que a tutela cautelar se revela como verdadeira garantia destinada a efetivar o direito ao processo devido, célere, econômico, efetivo e justo.
} 
Os processos judiciais devem ser organizados de forma a assegurar resultados os mais imparciais e justos possíveis. Ao decidir uma questão judicial os juízes devem atender uma série de requisitos que proporcionem uma decisão consentânea com aquilo apresentado no processo em igualdade de condições. Entre essas condições encontram-se os princípios do contraditório, da ampla defesa, do duplo grau de jurisdição, do juiz natural, da imparcialidade, da duração razoável do processo etc.

Conclui-se, portanto, que o processo, incluindo-se aqui a tutela cautelar, é instrumento qualificado, por garantir a efetividade de direitos, sobretudo aqueles relacionados com um processo justo, imparcial, razoável. Por tudo isso, não há como negar ao mesmo status de garantia fundamental, fadado à concretização desses direitos igualmente essenciais.

\subsection{Tutela Cautelar: Garantia Fundamental}

A Constituição fornece o fundamento último do ordenamento jurídico. Os valores fundamentais sobre os quais se erige o sistema passam a integrá-lo por meio da própria Carta que os positiva.

A consecução desses valores exige a intermediação de procedimentos estabelecidos em respeito a eles, para que se tomem decisões igualmente condizentes com tais ideologias. O processo (como um todo, inclusive o cautelar) aparece, então, como consectário lógico dos direitos insculpidos na constituição, sobretudo daqueles apostos em normas fundamentais, de aplicabilidade imediata e integral. ${ }^{8}$

Imperioso se faz, portanto, estabelecer procedimentos aptos a se chegar a decisões destinadas a concretizar os direitos do homem/cidadão, porquanto deverão ser dotados de determinadas características para cumprir a função sociopolítica assumida nesse contexto, pautados pelos princípios da proporcionalidade, ponderação, conformidade ou adequação dos meios etc.

A tutela cautelar não foge a tudo isso, entremostrando-se como verdadeira garantia fundamental, posto ser apta à proteção e efetivação de direitos fundamentais. Sobre o tema, ilustra J. J. Calmon de Passos (1984, p. 77-78):

A ideia de procedimento tornou-se determinante na evolução do direito público na última década, e a participação procedimental passou, ela mesma, a ser um direito fundamental. A ideia de procedimento faz-se indissociável dos direitos fundamentais.

A mera elaboração de uma Carta Magna, por maiores que sejam os direitos assegurados, não se mostra suficiente para efetivar o ideário no qual se inspirou, introduzindo-o nas estruturas sociais. Sua realização efetiva depende de procedimentos que a assegurem, somados ao engajamento maciço de todos os que fazem parte do processo.

O processo devido, incluindo-se o cautelar, revela-se instrumento apto à consecução e efetivação dos ideais constitucionais fundamentais, configurando-se em verdadeira garantia essencial, buscando e protegendo, em ultima ratio, a dignidade da pessoa humana.

\footnotetext{
${ }^{8}$ Constituição Federal, art. $5^{\circ}, \S 1^{\circ}$ - As normas definidoras dos direitos e garantias fundamentais têm aplicação imediata.
} 


\section{Conclusão}

Não obstante o desencontro doutrinário e jurisprudencial, acarretando na falta de tratamento pacífico acerca da proteção cautelar, certo se mostra sua importância e imprescindibilidade.

Seja entendendo-a como instrumento afeito à segurança de um processo dito principal, seja como protetivo do próprio direito, a tutela cautelar, como medida de urgência, revela-se verdadeiro garante da efetivação da própria dignidade do ser humano. É que de nada adiantaria se garantir direitos como liberdade, igualdade, moradia ou alimentação caso estes não pudessem ser implementados efetivamente.

O processo ordinário, ferramenta voltada para esse fim, entremostra-se ineficaz em casos nos quais o direito da parte pode padecer com o tempo, não podendo mais esperar para ser efetivado.

Em um contexto de Estado Social, propiciar aos cidadãos a oportunidade de ter concretizados seus direitos é tão importante quanto garanti-los formalmente. A tutela de urgência, gênero dentro do qual se encontra o processo cautelar, é meio apto e capaz de desempenhar esse papel, merecendo, bem por isso, atenção e tratamento condignos com sua importância.

Diante de tudo já exposto, não há outro caminho hermenêutico a seguir: o processo cautelar, à luz da Constituição Federal, tem, como objetivo primordial, a garantia de um processo efetivo. Trata-se, assim, em última análise, de garantia fundamental ao postulado do processo efetivo.

\section{REFERÊNCIAS}

ANDRADE, José Carlos Vieira de. Os direitos fundamentais na Constituição portuguesa de 1976. 2. ed. Coimbra: Almedina, 2001.

BARBOSA, Ruy. República: teoria e prática (textos doutrinários sobre direitos humanos e políticos consagrados na primeira Constituição da República). Petrópolis/Brasília: Vozes/ Câmara dos Deputados, 1978.

BEDAQUE, José Roberto dos Santos. Tutela cautelar e tutela antecipada: tutelas sumárias e de urgência. São Paulo: Malheiros Editores, 1998.

BONAVIDES, Paulo. Curso de direito constitucional. 10. ed. Brasil: Malheiros, 2000.

CAlmon DE PASsos, J. J. Comentários ao Código de Processo Civil. Vol. X, Tomo I. São Paulo: Revista dos Tribunais, 1984.

CANOTILHO, J. J. Gomes. Direito constitucional. 5. ed. Coimbra: Almedina, 1992.

GUERRA FILHO, Willis Santiago. A Filosofia do Direito - aplicada ao direito processual e à teoria da Constituição. São Paulo: Atlas, 2001.

MACHADO HORTA, Raul. Constituição e Direitos Individuais. Revista de Informação Legislativa, a. 20, nº 79, junho/set.

MAGALHÃES, José Luis Quadros de. Direitos humanos. 1. ed. São Paulo: Juarez de Oliveira, 2000. 
MIRANDA, Jorge. Manual de direito constitucional: tomo IV: direitos fundamentais. 3. ed. Coimbra: Coimbra, 2000.

MORAES, Alexandre de. Direitos Humanos Fundamentais. 2. ed. São Paulo: Atlas, 1998. . Direito constitucional. 18. ed. São Paulo: Atlas, 2005.

PASSOS, J. J. Calmon de. Comentários ao Código de Processo Civil. São Paulo: Revista dos Tribunais, 1984, vol. X, Tomo I, p. 46.

SARLET, Ingo Wolfgang. A eficácia dos direitos fundamentais. 2. ed. Porto Alegre: Livraria do Advogado Editora, 2001. , (org.). Constituição, direitos fundamentais e direito privado. Porto Alegre:

Livraria do Advogado, 2003.

SARMENO, Daniel. Direitos fundamentais e relações privadas. Rio de Janeiro: Lúmen Júris, 2004.

SILVA, De Plácido e. Dicionário vocabulário jurídico. 11. ed. Rio de Janeiro: Forense, 1993.

SILVA, Jaqueline Mielke. Tutela de urgência: De Piero Calamandrei a Ovídio Araújo Batista da Silva. Porto Alegre: Verbo Jurídico, 2009.

SILVA, José Afonso. Curso de direito constitucional positivo. São Paulo: Malheiros, 2000.

SILVA, Virgílio Afonso da. A constitucionalização do direito: os direitos fundamentais nas relações entre particulares. São Paulo: Malheiros, 2005.

VIEIRA, Oscar Vilhena. Direitos fundamentais - uma leitura da jurisprudência do STF. São Paulo: Malheiros, 1999.

ZIMMERMANN, Augusto. Curso de direito constitucional. Rio de Janeiro: Lúmen, 2002.

\section{INJUNCTIVE RELIEF AS FUNDAMENTAL GUARANTEE}

Abstract: The present study examines the injunctive relief from several perspectives. It considers the two most outstanding schools that deal with the subject, materialized in the theories of Piero Calamandrei and Ovidio Araújo Batista da Silva, which acquires the status of a fundamental guarantee. The research was developed within a descriptive-analytical approach, such as bibliographic and documentary.

Keywords: Provisional proceedings; Injunctive relief; Due process of law; Piero Calamandrei; Ovídio Araújo Batista da Silva; Urgency relief; Fundamental guarantee.

Data de recebimento: dez/2012 - Data de aprovação: mar/2013 